\title{
ASPECTS OF INEBRIETY IN AMERICA.
}

\section{BY EDWARD HUNTINGTON WILLIAMS, M.D.,} Author of "The Question of Alcohol," etc.

THE fight against inebriety in America presents some curious aspects. Liquor legislation is a dominating political element which has been gaining impetus for half a century, and is now acutely active in every State. Yet to-day the per capita consumption of alcohol, particularly the consumption of concentrated liquors, is greater than ever before. The official Government records on this point need no elaboration. They show that fifty years ago the annual per capita consumption of liquor was 6.43 gallons; in 1914 the per capita consumption had increased to something over 23 gallons. Yet these fifty years correspond precisely with the period of most active legislation against alcohol.

It is only recently, however, that it has become possible to measure the effects of liquor legislation with any degree of accuracy. Hitherto such legislation has been too desultory, too limited in time of application. Moreover, reliable statistics have been wanting. But the last Government Census Reports, covering every phase of social and economic conditions during recent years, are now available, and afford a basis for measuring the effects of legislation in the country as a whole, and in restricted districts. Deductions can only be made from indirect evidence in certain instances, however, since from a statistical standpoint liquor does not exist in legally "dry" communities. But the fact that the records of crime, disease, and degeneracy are complete, and that these conditions are dependent in a large measure upon the abuse of alcoholics, make the exhaustive Government reports a means of illuminative comparison.

Conditions in America make such comparisons peculiarly pertinent, probably more so than in any other country. In the 
United States there are certain large communities which are closely similar in every important particular, except in the matter of liquor legislation. For example, there are two large and important States, Maine and Kansas, in which the sale of any form of alcoholic beverage has been forbidden for more than thirty years. The State of Maine does not afford a field for entirely fair comparison, as its admittedly bad record may be partly the result of geographical conditions entirely different from its neighbours. Kansas, on the contrary, offers an ideal field for comparison with the adjoining State, Nebraska. These two States, having a combined area that is 25 per cent. greater than the British Isles, are almost exactly alike in seographic position and economic conditions. The Census Report shows that these States have practically the same percentage of native whites, foreign-born whites, negroes, ratio of males to females, percentage of urban and rural population, and increase in population during the census period. It may be added that there are no corresponding areas in America where the standards of intelligence and morality are higher. At the close of the census period, Kansas had 1,971 prisoners and juvenile delinquents, while Nebraska had 789. Kansas had 74 almshouses with 735 inmates, while Nebraska had 51 almshouses with 551 inmates. Kansas had $172 \cdot 2$ insane persons per 100,000 inhabitants, Nebraska had $167^{\circ} 0$. Moreover, Kansas decreased only 10 insane persons per 100,000 inhabitants, while Nebraska declined 28. There were $\mathbf{2 . 2}$ per cent. illiterate persons in Kansas, as against 1.9 per cent. in Nebraska. And the number of farms cumbered by mortgages in Kansas was $44^{\circ} 8$ per cent., while in Nebraska the percentage was $39^{\prime} 4$. Thus Kansas' record of conditions that are vitally affected by the abuse of alcohol does not compare favourably with that of her sister State. Yet theoretically her record should be much better, since Kansas prohibits the sale of all intoxicants, while Nebraska permits such sales under carefully regulated restrictions.

Broadening the view for comparison to the country as a whole, it appears that Kansas, in 1913, had a higher rate of violent deaths than 29 States in which the form of liquor legislation was similar to that of Nebraska. There were 38 of these States at that time. The rate of suicide was higher in Kansas than in 20 such States; the ratio of divorce to marriages was higher than in 27; and the percentage of Church membership was lower than in 38. It is also a matter of official record that, 
whereas 1 person in 9 in the country as a whole had a bank savings account, only 1 person in 87 had such an account in Kansas. Moreover, the average savings account in Kansas was $\$ 231^{\circ} 69$, as against $\$ 439^{\circ} 07$ per depositor in the country as a whole.

I present these statistics taken from the Report of the United States Commissioner of Internal Revenue, and the last Statistical Abstract, since the results of Kansas' conscientious efforts to carry out an ideal form of liquor legislation seem most significant, and because future liquor legislation in the country as a whole is likely to be greatly influenced by conditions in this pioneer State.

Undoubtedly there is a very close association pathologically between inebriety and the drug-addictions caused by morphine, heroin, and cocaine. The meagre statistics available at present indicate that liquor legislation has an important bearing upon these kindred evils. It is contended by the opponents of prohibitive legislation that such drastic measures increase the use of these other harmful narcotics. Exhaustive statistics are not available at present, but the number of insane drug-habitues in our public institutions offers suggestive evidence.

In New York State, for example, where the sale of intoxicants is merely restricted, but in which the record for drug-addictions is somewhat higher than in most of the other States, we find one insane drug-taker to every 386 cases of other forms of insanity. This proportion, however, is considerably lower than in any of the prohibition States at a corresponding period. Thus the proportion in Maine was 1 to 76; in Kansas, 1 to 89; in North Carolina, 1 to 84; in Georgia, 1 to 42 ; in Tennessee, 1 to 74 ; in Mississippi, 1 to 23 ; in Oklahoma, 1 to 9 . Or, stated in another way, these States have from four to forty times as many insane drug-takers as New York.

It should be explained that most of these States have a large negro population, one of them having fully as many coloured inhabitants as white. In these "negro States" the laws prohibiting liquor traffic are strictly enforced-at least as far as the coloured man is concerned. Yet in these very communities drug-taking, particularly " cocaine-sniffing," is unusually prevalent; and it is significant that this dangerous habit was practically unknown"in those regions until after the sale of liquor was prohibited. It is significant, also, that the laws forbidding the sale vor. XIII. 
of cocaine do not prevent the negro from obtaining the drug, even in communities where prohibitive laws against liquor traffic are effective.

It is apparent, therefore, that even in relatively small communities the results of our attempts to solve the inebriety problem by direct legislation are not encouraging. Whether we consider these communities separately, or take the record of the country as a whole, we are confronted by the disconcerting fact that the per capita consumption of alcohol steadily increases.

From a medical view-point it appears that one very important element in the fight to suppress inebriety is ignored by every form of legislation now in force-namely, the inebriate himself. In the opinion of most qualified observers, inebriety is a disease dependent upon a constitutional defect-in effect a latent powder mine which is not caused, but simply exploded by the alcohol fulminate. Legislation aimed merely at the exciting spark, therefore, seems scarcely more rational than attempts to perfect a safe form of miner's lamp instead of cleaning out the mine.

A different attitude toward the inebriate, which involves a radical departure from our present method of punishing him for his symptom instead of treating the underlying disease, would be a stepping-stone toward correcting the focus of the tendency to alcoholism. Yet this important step has been very largely ignored in our eagerness to abolish the great evil by one sweeping legislative blow.

Another vitally important element in the temperance fight is the adolescent. The necessity of protecting young persons against alcoholic indulgence is perhaps the only point of agreement between all temperance factions. Opinions as to the best means of accomplishing this, however, are widely divergent. But thus far the net results of all methods is not encouraging. The proportion of juvenile delinquents is quite as high in communities where liquor cannot be legally sold as in those having a more tolerant form of legislation.

Judged by results, therefore, we seem to have placed too great reliance upon impetuosity and massed frontal attack in our fight against the liquor evil. Such methods appear to be quite as ineffectual in this great moral conflict as in the more sanguinary form of modern warfare. 